\title{
COMPARING PROCESS-BASED NET PRIMARY PRODUCTIVITY MODELS IN A MEDITERRANEAN WATERSHED
}

\author{
${ }^{\mathrm{a}}$ Cenk Donmez, ${ }^{\mathrm{a}}$ Suha Berberoglu, ${ }^{\mathrm{b}}$ Matthew Forrest, ${ }^{\mathrm{c}}$ Ahmet Cilek, ${ }^{\mathrm{b}}$ Thomas Hickler \\ ${ }^{a}$ Cukurova University, Landscape Architecture Department, 01330 Adana, Turkey (cdonmez, suha@cu.edu.tr) \\ ${ }^{\mathrm{b}}$ Goethe-University, Biodiversity and Climate Research Centre (BiK-F), Senckenberganlage 25 D-60325 \\ Frankfurt am Main, Germany (thomas.hickler, matthew.forrest@senckenberg.de) \\ ${ }^{c}$ Ahi Evran University, Landscape Architecture Department, 40100, Kirsehir, Turkey ahmet.cilek@ahievran.edu.tr
}

\section{Commission VII, WG VII/1}

KEY WORDS: NPP Modelling, Remote Sensing, Percent Tree Cover, Model Comparison, CASA, LPJ-GUESS.

\section{ABSTRACT:}

The aim of this study was to compare the estimation capability of two different process-based NPP models (CASA and LPJGUESS) in a Mediterranean watershed. Remotely sensed data and climate time series (temperature, precipitation and solar radiation) were input to these models in the example of Goksu River Basin which is located in the Eastern Mediterranean Part of Turkey.

The comparison of these models was based on output variables. These variables were divided into three groups; i) spatiallyinterpolated total NPP estimations, ii) NPP distribution of land cover classes, iii) annual and monthly based NPP variations. Different model approaches were evaluated within their capability to prove the relationship between annual / monthly NPP and major climatic variables. The effect of vegetation distribution on the accuracy of models was examined. The uncertainities of the CASA and LPJ-GUESS model were evaluated by incorporating remotely sensed data, percent tree cover and ground measurements. The differences between model outputs were guided to enhance modelling strategies by means of remotely sensed data and other input parameters.

\section{INTRODUCTION}

Net primary productivity (NPP) is defined as the net flux of carbon from the atmosphere into green plants per unit time. It has significant importance for the carbon cycle and an critical indicator of ecosystem sustainability. Accurate estimate of NPP is critical to understanding the carbon dynamics within the atmosphere-vegetation-soil continuum and the response of terrestrial ecosystem to future climate warming.

The models to estimate NPP are groupped in three major categories: i) remote sensing based models that use data from different sensors as their major inputs (CASA, GLOPEM, TURC), ii) process-based models that simulate carbon fluxes using vegetation structure (BIOME, LPJ-GUESS), iii) models simulate carbon using both vegetation structure and carbon fluxes (DOLY, HYBRID)

Those models are used to estimates NPP in global and regional scales. However, NPP estimates show significant differences among different models in different data sources. The differences of the model estimations cause many uncertainties that reduce the precisions and reliability of the models. Hence, the comparison of different model estimations are needed to evaluate different model performances to improve the accuracy of the models by varying input parameters. Inter-comparison of NPP models provides an effective tool to realize capability of each model to represent NPP patterns under climatic variations.
The aim of this study were to compare and evaluate two different approaches (CASA and LPJ-GUESS) by modelling mean annual NPP and its spatial distribution in a semi-arid Mediterranean watershed. The comparison of these approaches was carried out on the basis of their time steps, data inputs and spatially distributed outputs. The relationship between model outputs were analysed to examine the linear trends in representation of NPP.

\section{MATERIAL and METHODS}

\subsection{Study Area}

The study area selected for this study is Goksu Watershed located in the Eastern Mediterranean region of Turkey (Figure $1)$.

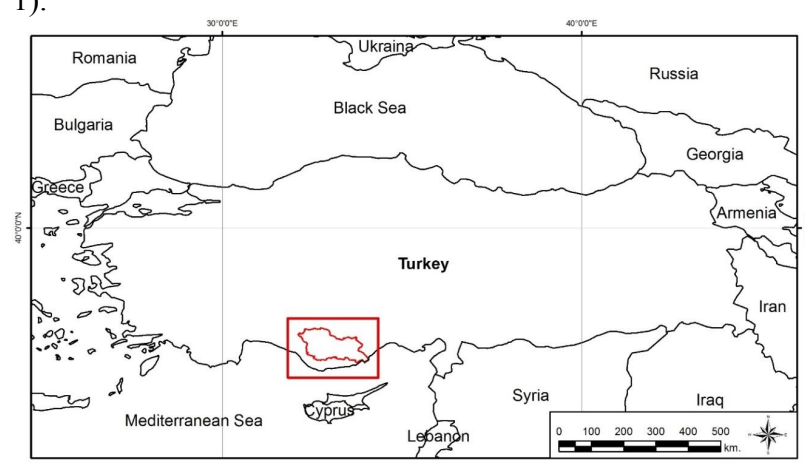

Figure 1. Location of the Goksu Watershed. 
The basin covers approximately $10000 \mathrm{~km}^{2}$. The land cover types of the region comprise Mediterranean evergreen needleaf forests with Turkish pine (Pinus brutia) and Juniper (Juniperus excelsa), grasslands and bare grounds. The climate is characterized by prevailing Mediterranean with mild and rainy winters and hot and dry summers with a mean annual precipitation of approximately $800 \mathrm{~mm}$. Mean annual temperature is $19^{\circ} \mathrm{C}$.

\subsection{Material}

Two sets of remotely sensed images were utilized for the CASA model simulation; i) a LANDSAT TM/ETM data set comprising five scenes from 1999-2003, ii) Three sub-scenes of Geo-EYE imagery representing different types of forest cover were used as training and testing data for percent tree cover. The topographic maps in 1:25.000 scale were used to derive Digital Elevation Model (DEM). The forest maps were utilized in land cover mapping process.

LPJ model required time series data and soil texture information. The time series data comprise precipitation, temperature and solar radiation on daily basis. Soil information was obtained by field campaigns and expert opinions and mapped in GIS environment. Time series and soil information were converted available model input format and integrated into LPJ modelling process.

\subsection{Methods}

The method used in this study consisted three phases; i) Modelling NPP using the CASA model, ii) Modelling NPP using LPJ-GUESS, iii) comparison of the model outputs.

\subsubsection{The CASA Model Application}

The CASA model computes the monthly NPP flux as net fixation of $\mathrm{CO} 2$ by vegetation on the basis of light-use efficiency. Thus, calculates NPP is calculated as a function of the driving energy for photosynthesis, the absorbed photosynthetically active (400 to $700 \mathrm{~nm}$ ) solar radiation (APAR), and an average light utilization efficiency $(\varepsilon)$ (Potter et al., 2003). The fundamental relation in the CASA model is

$$
\begin{gathered}
\mathrm{NPP}=\mathrm{APAR} \times \varepsilon \\
\mathrm{NPP}=\mathrm{f}(\mathrm{NDVI}) \times \mathrm{PAR} \times \varepsilon \times \mathrm{g}(\mathrm{T}) \times \mathrm{h}(\mathrm{W})
\end{gathered}
$$

where APAR (in megajoules per square meter per month) is a function of Normalized Difference Vegetation Index (NDVI) and downwelling photosynthetically active solar radiation (PAR) and $\varepsilon$ (in grams of $\mathrm{C}$ per megajoule) is a function of the maximum achievable light utilization efficiency $\varepsilon$ adjusted by functions that account for effects of temperature $g(T)$ and water $\mathrm{h}(\mathrm{W})$ stress. Whereas previous versions of the CASA model (Potter et al, 1993, 2004) used a normalized difference vegetation index (NDVI) to estimate FPAR, the current model version instead relies upon canopy radiative transfer algorithms (Knyazikhin et al. 1998), which are designed to generate improved FPAR products as inputs to carbon flux calculations. The model was utilized to predict annual regional fluxes in terrestrial net primary production at variable degrees of $\mathrm{C}$, depending on the yearly conditions, with terrestrial net production.
Several diverse datasets were used in this research. Calculation of annual terrestrial NPP is based on the concept of light-use efficiency, modified by temperature, rainfall values and solar radiation scalars. In addition, percentage of tree cover, land cover map of the region, soil texture and NDVI (normalized difference vegetation index) were used to constitute this model.

\section{Climate Data}

Monthly precipitation, air temperature and solar radiation were used as the climate data sets. These variables were based on 9 years (2000-2009) records from the meteorological stations in and around the study region. Climate variables were interpolated together with DEM using co-kriging method and mapped on monthly basis.

\section{Mapping Land Cover}

A comprehensive land cover map was used as one of the inputs of the CASA model. This map was derived from two data sources: LANDSAT ETM image acquired in 2003, ground truth data from field surveys. Image classification was carried out using maximum likelihood algorithm with supervised training. The classifier was provided with the spectral reflectance properties of each class in the form of the mean reflectance for each spectral waveband and the associated covariance matrix. This data was generated from a selection of sample training pixels for each class provided from ground data. The output comprised the land cover classes with $30 \mathrm{~m}$ spatial resolution initially. Accuracy analysis was carried out by comparing the classification map and ground truth data.

\section{Soil texture}

The soil texture data file is based on FAO soil texture classification which has 7 classes. The dominant soil type in a soil unit, the designation "coarse", "medium", "fine", or a combination of these based on the relative amounts of clay, silt, and sand present in the top $30 \mathrm{~cm}$ of soil. The regional soil maps in 25.000 scale was utilized for this study and soil texture classes were assigned on the basis of estimated clay content according to FAO (Potter et al. 2003).

\section{NDVI}

Monthly NDVI images derived from 20 LANDSAT scenes recorded in between May 2001 and November 2002. Four images were combined to comprise the study region. The monthly composites were created and bands 4 and 3 were used to produce NDVI. Monthly NDVI images ranging between 0 and 1 were the input to CASA model.

\section{Percent Tree Cover}

Percent tree cover map was one of the most significant input of the CASA model. The Regression Tree (RT) algorithm was utilised to predict percent tree cover within a Mediterranean type forest using LANDSAT data. RT is a piecewise constant or piecewise linear estimate of a regression function, constructed by recursively partitioning the data (Loh, 2002). The methodology for deriving percent tree cover with RT consisted of five steps for this study (Figure 6) (Donmez et al., 2011): i) generate reference percentage tree cover data, ii) derive metrics from LANDSAT data, iii) select predictor 
variables, iv) fit RT models, v) undertake accuracy assessment and produce final model and map.

\subsubsection{The LPJ-GUESS Application}

LPJ-GUESS is a flexible, modular modelling platform for simulating vegetation dynamics and biogeochemical cycles at local to global scales. It includes the widely used LundPotsdam-Jena Dynamic Global Vegetation Model (LPJDGVM; Sitch et al., 2003), but vegetation dynamics (tree establishment and mortality, as well as tree size distribution, canopy structure and disturbance) can also be represented in more detail, adopting a forest gap model approach (Shugart and West, 1980). The global parameterization of the model version formed the basis of the regional parameterisation for Turkey. However, the plant functional types (PFTs) were modified by the exclusion of tropical tree and tropical grass PFTs and the inclusion of three Mediterranean PFTs. The Mediterranean PFTs comprise a deep-rooted evergreen Mediterranean shrub, a shallow-rooted raingreen Mediterranean shrub and a temperate needle-leaved evergreen tree. These PFTs are based on the vegetation of Hickler et al. 2012 but with bio-climactic limits derived from measured coldtolerances of Mediterranean vegetation and visual comparison of growing degree days on a $5 \mathrm{C}$ base with the known limits of Mediterranean vegetation. A location in the model is represented as a stand, i.e. an area with identical environmental conditions, defined by soil texture and a set of climatic variables. The spatial extent of a stand is flexible and simply given by the spatial resolution of environmental driver variables, here a grid of $1 \mathrm{~km} \times 1 \mathrm{~km}$. For each stand, vegetation is simulated in a number of replicate patches (without a specific location within the stand), in which individual tree establishment, mortality and patch-replacing disturbances are simulated stochastically (as commonly done in forest gap models).

\subsubsection{Testing models by comparison}

An inter-comparison of terrestrial biogeochemical models used in this study was carried out using primary outputs connected to a range of ecosystem processes (NPP). A linear regression technique was used to identify the differences of model. CASA and LPJ models use different input data sets to simulate NPP.
For the comparison processes, these data sets are standardized. However, this standardization is not possible in some cases. For example, the CASA model requires a spatial vegetation map including defined classes according to behaviours and outputs. Random pixels were selected from the model NPP maps and the regression analyses were realized using these pixels. The correlation coefficient $\left(\mathrm{r}^{2}\right)$ was investigated between model outputs to prove the linear relationship and differences between LPJ and CASA models.

The spatial resolution was standardized into $1 \mathrm{~km}$ and $\mathrm{r}^{2}$ was calculated for each selected pixel. The NPP values for the each pixel were obtained from the common LPJ and CASA model outputs and correlated.

The differences between model NPP estimations were identified by consisting the regression analyses. The in cooperation of the model outputs was significant to identify the capability of the different model behaviours on NPP estimation in local scale.

\section{RESULTS}

\section{Uncertainty of Input Parameters}

The CASA model utilises vegetation maps and ancillary data to prescribe vegetation structure to simulate the biogeochemical fluxes on the basis of soil and climate characteristics. This model describes functional changes within vegetation particularly and ignore the vegetation redistribution.

The LPJ model is a DGVM that simulates ecosystem structure and functions and applied to potential vegetation. It estimats NPP as the difference between two processes that are modelled independently; Gross Primary Production (GPP) and Autrophical Respiration (RA).

Comparison of the broad features of the NPP Models is given in Table 1.

Additionally, the spatial and temporal resolutions of the input sets vary in agreement of the modelling strategy. Input data categories of NPP models used in this study are shown in Table 2 .

Table 1. Comparison of the broad features of the CASA and LPJ Models

\begin{tabular}{lcll}
\hline \multicolumn{1}{c}{ Model } & Temporal Resolution & \multicolumn{1}{c}{ Influenced by } & \multicolumn{1}{c}{ Strategy } \\
\hline CASA & 1 month & $\mathrm{NPP}=f\left(\varepsilon^{*}, R S, f P A R, T, E E T, P E T\right)$ & NPP applied by empirically derived Light Use Efficiency derived \\
LPJ-GUESS & 1 day & $\mathrm{GPP}=f\left(\varepsilon^{*}, R S, f P A R, T, \mathrm{VPD}, L A I\right.$, & Vegetation structure and physiological processes are simulated bu \\
& & $S W, R A)$ & ccoupling C and water balance, pheonology \\
& $\mathrm{NPP}: \mathrm{GPP}-\mathrm{RA}$ & \\
\hline
\end{tabular}

Rs: Solar radiation PET: Potential evapotranspiration EET: Estimated evapotranspiration, $T$ : Temperature, $W$ : Water capacity, $R A$ : Plant autotrophic respiration, LAI: Leaf Area Index

\begin{tabular}{llcccc}
\hline & \multicolumn{3}{c}{ Selected Inputs } & \multicolumn{2}{c}{ Selected Outputs } \\
Model & Type & $\begin{array}{c}\text { Vegetation } \\
\text { Distribution }\end{array}$ & $\begin{array}{c}\text { Satellite } \\
\text { fPAR }\end{array}$ & $\begin{array}{c}\text { Biogeochemic } \\
\text { al fluxes }\end{array}$ & LAI \\
\hline CASA & $\begin{array}{l}\text { Satellite } \\
\text { based }\end{array}$ & $\mathrm{X}$ & $\mathrm{X}$ & $\mathrm{X}$ & \\
LPJ & $\begin{array}{l}\text { Seasonal } \\
\text { fluxes and } \\
\text { veg.structure }\end{array}$ & $\mathrm{X}$ & & $\mathrm{X}$ & $\mathrm{X}$ \\
\hline
\end{tabular}

Table 2. Input data categories of CASA and LPJ models

Parameters using in modelling processes are similar in remote sensing and ecosystem processes models. The main differences are the use of meteorological variables and deriving PPAR. Te CASA model utilises NDVI to derive fPAR by applying different algorithms;

$$
\text { CASA } f P A R=\min \left\{\left(S R-S R_{\min }\right) /\left(S R_{\max }-S R_{\min }\right), 0.95\right\}
$$




\section{$S R=(1+N D V I) /(1-N D V I)$}

However, the accuracy of fPAR is still an unsolved problem due to ground measurement constrains.

The regional meteorology distribution is based on the spatial interpolation of station measurements. The interpolation precision is an important issue that influences the accuracy of NPP simulations (Liu et al, 2010). The multiple regression methods had a reasonable performance by introducing elevation and location. The CASA model utilises spatiallyinterpolated meteorological maps incooperated the elevation.

A wide datasets were used in this study to constitute model simulations. A detailed land cover used a an input in the CASA model process are shown in Figure 2.

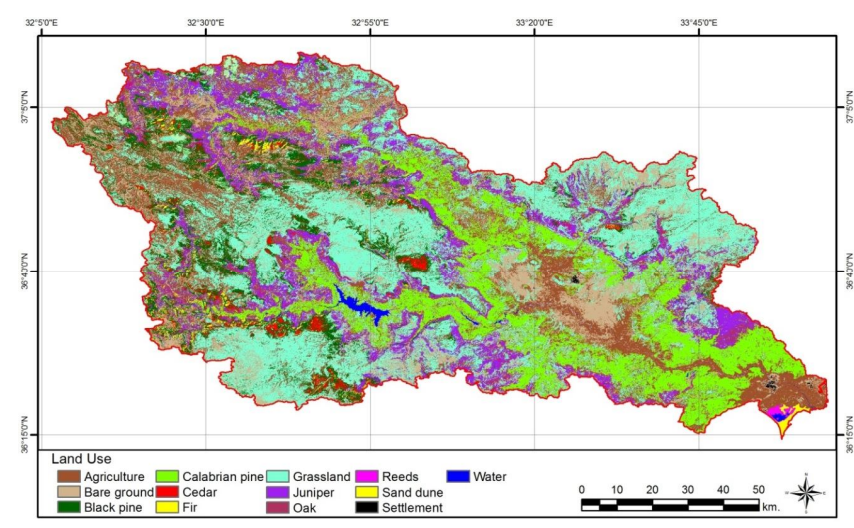

Figure 2. Land Cover Map of Goksu Watershed used a an input in CASA Model.

The forest stands of Goksu Basin were combined to two formation classes as NLEF and BDF. The forest NPP estimation using CASA model was based on those two classes that comprise the main forest types of Goksu Basin. NLEF comprises Juniperus excelsa, Pinus nigra, Pinus brutia, Cedrus libani and Abies cilicica. BDF comprises only Quercus sp., respectively.

The Goksu Basin located in Mediterranean region is characterized within its sparse vegetation. The complexity of its terrain in respect to the soil types and topography greatly influence reflectance from sparse cover of the Mediterranean forests. Particularly, high reflectance from the soil causes a significant albedo effect, and hence, overwhelms reflectance from the vegetation component, thus leading to under estimation of NPP (Berberoglu et al., 2007). Thus, the percent tree cover map derived using the RT method improved the discrimination of vegetation cover by assisting in the exploration of the relationships between LANDSAT spectral bands and biophysical variable of NDVI. This relationship assisted to calibrate the model along the entire tree cover and other land cover types. The percent tree cover map used a major input of the CASA model is shown in Figure

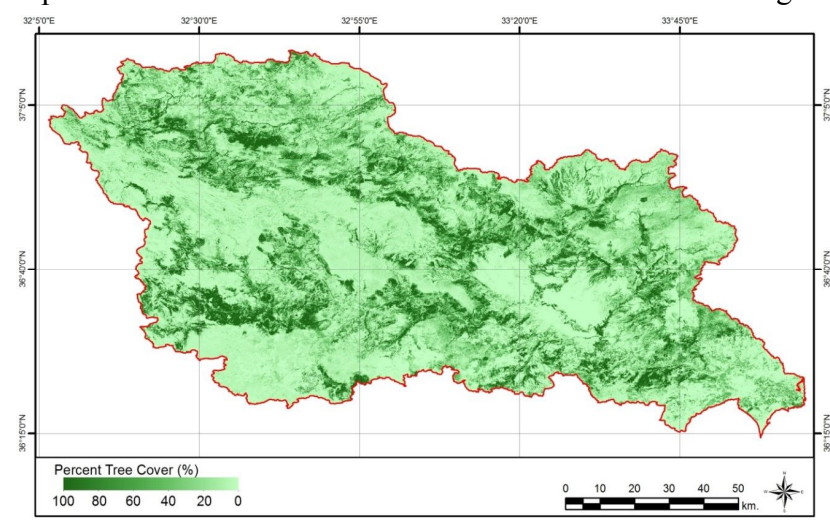

Figure 3. Percent Tree Cover Map of Goksu Watershed used a an input in CASA Model.

The climate variables including precipitation, air temperature and solar radiation play a significant role in understanding the seasonal NPP changes of differents land cover classes. Hence, integration of climate variables and spatial ancillary data including land cover and percent tree cover maps to the regional models may increase the potential on NPP representation of the complex environments. Such approaches improve in understanding and assessing the local and regional consequences of climate change on the productivity of the complex and rich ecosystems such as Goksu Basin.

\section{Comparising the CASA and LPJ Outputs}

Time step plays an important role in estimating NPP. The CASSA model outputs comprised monthly NPP maps. The NPP was estimated on daily basis with LPJ-GUESS. Monthly and daily NPP estimations form those models were amalgamed and total NPP maps were derived. The comparison of model outputs were carried out using total NPP maps.

Annual total NPP map of the Goksu Basin derived from the CASA model is shown in Figure $4(30 \mathrm{~m})$ and Figure $5(1-\mathrm{km})$. Annual total NPP map derived from LPJ model is shown in Figure 6 (1-km).

Monthly NPP changes in land cover classes of Goksu Basin were estimated with CASA model. The NPP of major land cover classes were aggregated and total annual NPP was estimated. Monthly NPP maps revealed that mean monthly NPP ranged from 12.9 to $144.07 \mathrm{gC} \mathrm{m} 2$ month-1. A significant increase was determined from March to April within spring season in the entire basin. Slight changes in NPP is realised from April to June until a dramatic decrease occurs in July. 


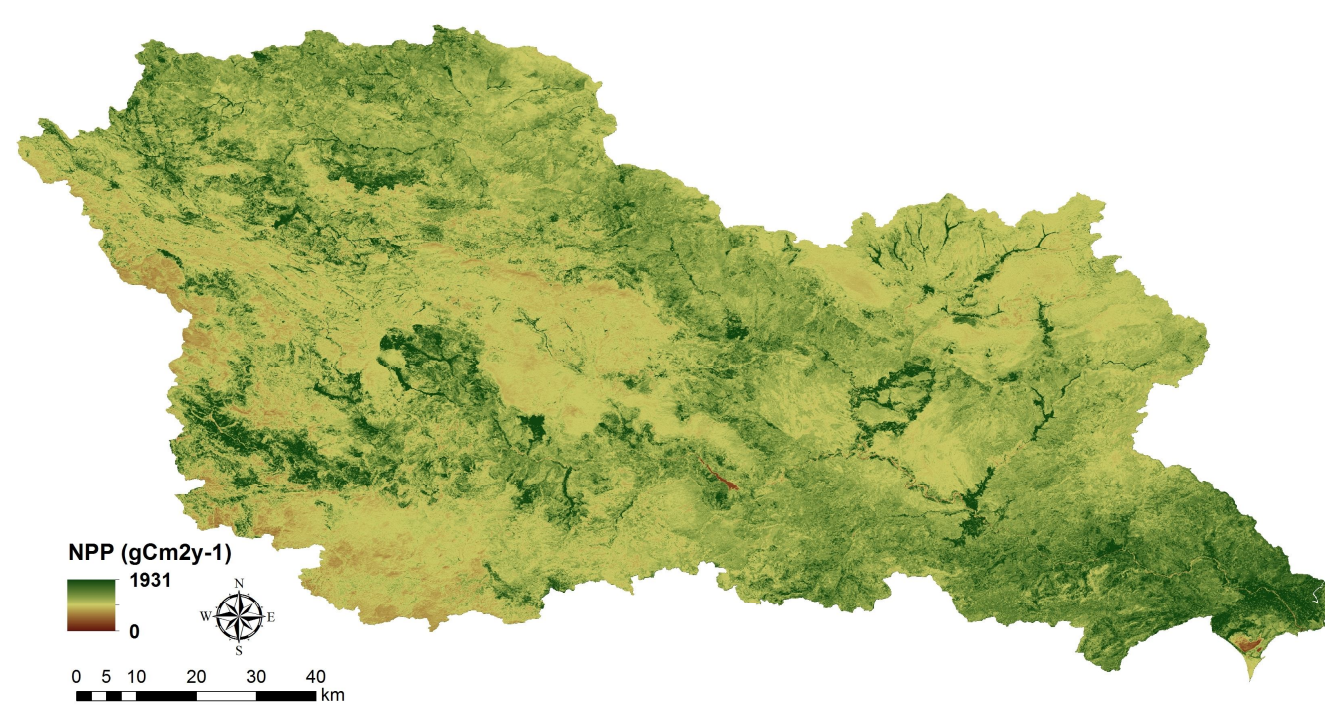

Figure 4. Total Annual NPP Map derived from the CASA-30 m.

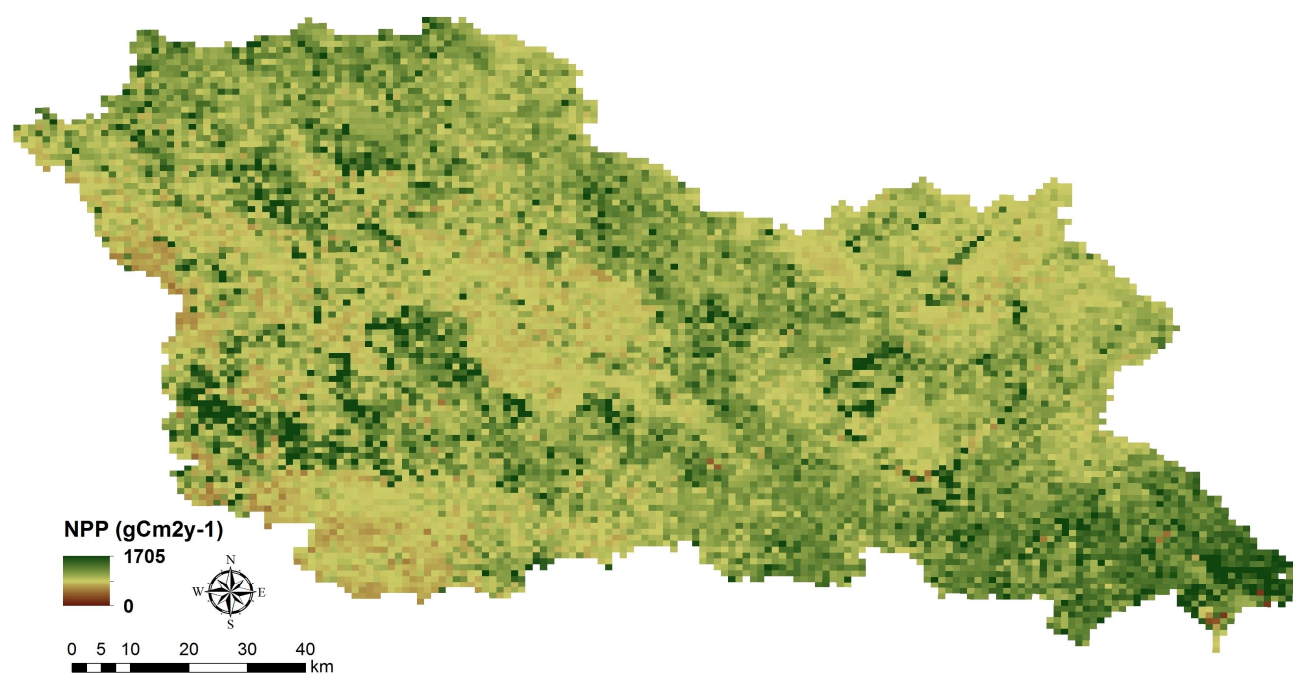

Figure 5. Total Annual NPP Map derived from the CASA-1 km.

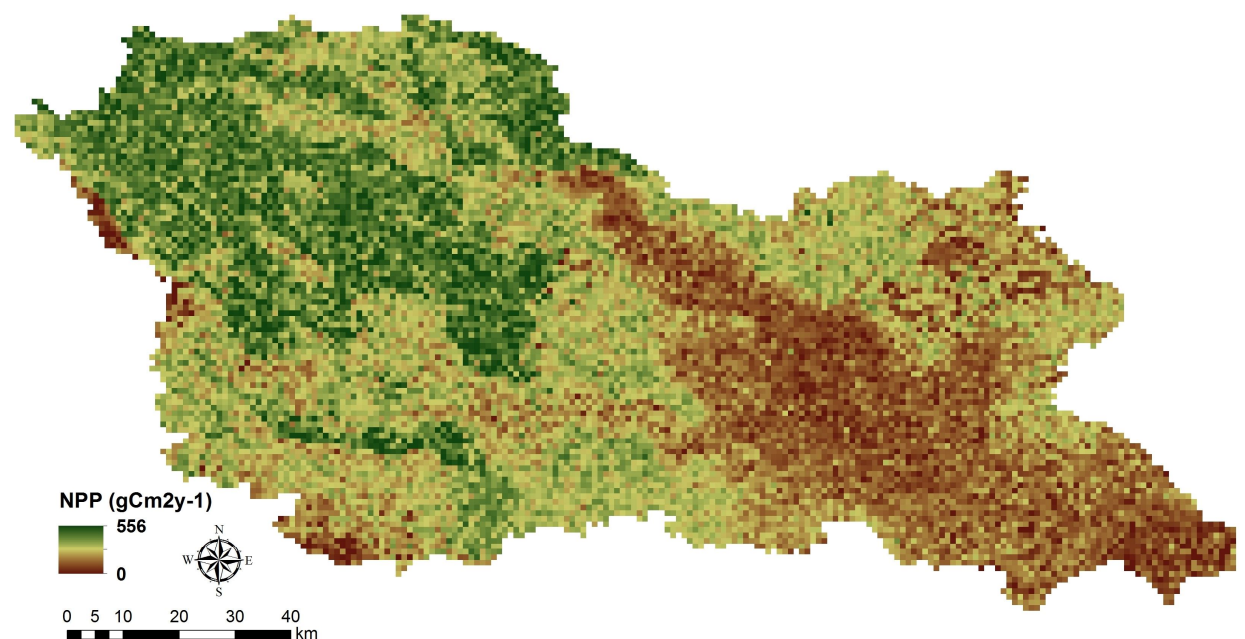

Figure 6. Total Annual NPP Map derived from the LPJ. 
The CASA and LPJ model outputs showed significant differences in terms of their vegetation representation. Annual NPP was estimated as $705 \mathrm{gCm}^{2} \mathrm{y}-1$ within CASA model. In respect to the CASA model simulations, the NPP was underestimated in watershed scale. The total annual NPP was estimated as $556 \mathrm{gCm}^{2} \mathrm{y}-1$ using LPJ model.

The plots of different model outputs are shown in Figure 7. a)

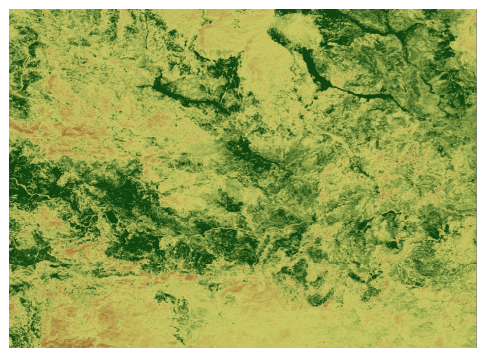

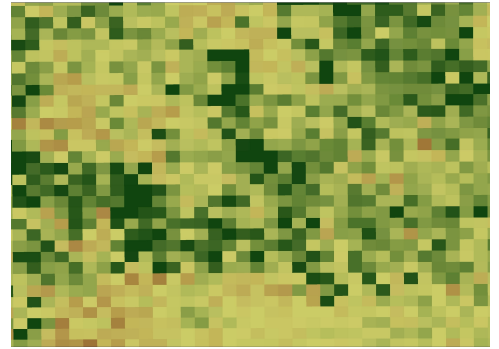

c)

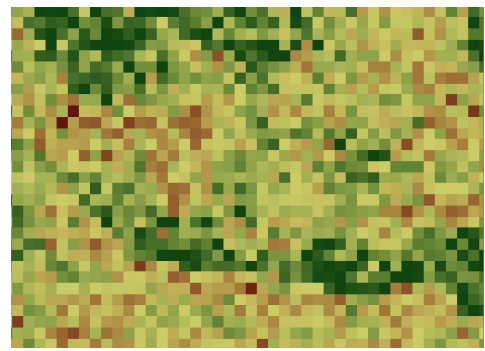

Figure 7. The plots of different model outputs; CASA-30m (a), CASA-1 km (b), LPJ-GUESS- $1 \mathrm{~km}$, (c).

The spatial distribution of NPP also showed large differences in both model estimations. The land cover classification and soil texture data biased potentially the spatially distributed estimation of NPP in CASA model simulations. The output NPP maps in CASA model associated with different land cover

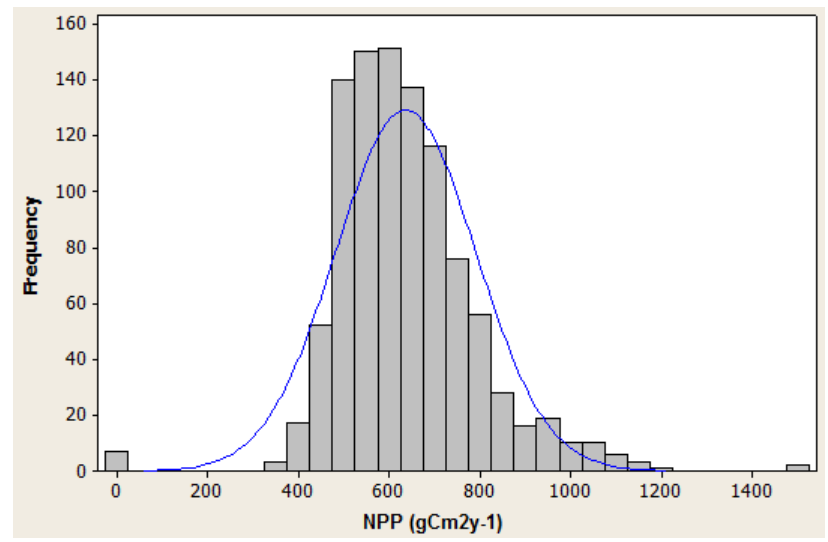

types and percent tree cover. The grassland and bare soil areas were more distinctive in NPP maps derived from the LPJ model.

The histograms derived using random pixels of different model NPP maps are given in Figure 8.

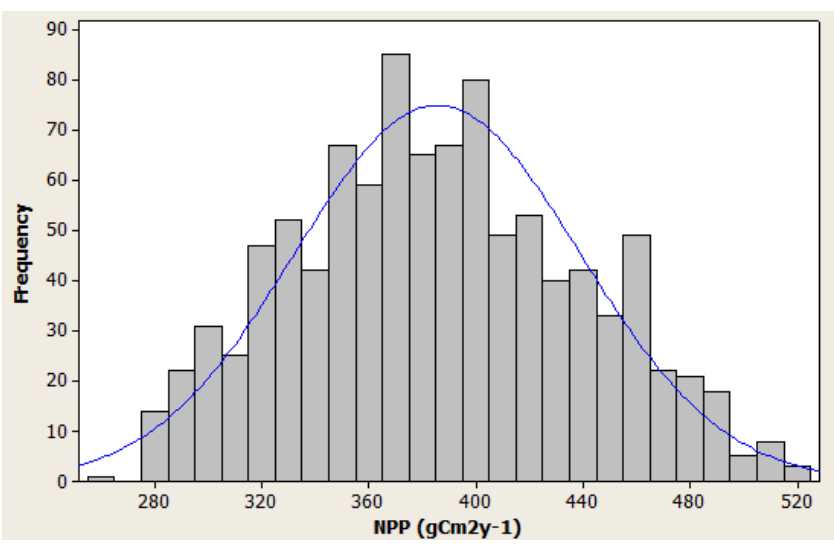

Figure 8. Histograms of CASA (Left) and LPJ-GUESS (Right) NPP maps

The CASA model NPP estimates range approximately from 200 to $1200 \mathrm{gCm}^{2} \mathrm{y}-1$. This range showed that the CASA model was able to capture NPP differences in rich vegetation diversity.

The LPJ-GUESS NPP estimates range from $280-550 \mathrm{gCm}^{2} \mathrm{y}-1$. Thus, the LPJ-GUESS estimated NPP in a low frequency. The standart deviation for CASA model estimations was 53 and 163 for the LPJ. The model NPP estimation was also compared for each land cover classes. A comparison of modelled NPP for random grid cells was realized for each class. The values of random grid cells of different NPP outputs were correlated and the linear relationship of model NPP outputs was defined. The total annual NPP estimations for the land cover classes derived from CASA and LPJ-GUESS are shown in Table 3.

The annual total NPP estimations of the CASA and LPJGUESS for each land cover classes showed large differences. Needleleaf Evergreen Forest (NLEF) was estimated 702
$\mathrm{gCm}^{2} \mathrm{y}-1$ within CASA model and $375 \mathrm{gCm}^{2} \mathrm{y}-1$ within LPJGUESS. Moreover, the difference in annual total NPP of the Broadleaf Forest formations are calculated approximately -332 $\mathrm{gCm}^{2} \mathrm{y}-1$.

Table.3. Total annual NPP estimations for the land cover classes.

\begin{tabular}{lcc}
\hline Land Cover Classes & CASA (1-km) & LPJ-GUESS (1-km) \\
\hline NLEF & 702 & 375 \\
BDF & 726 & 394 \\
Agriculture & 657 & 369 \\
Grasslands & 698 & 397 \\
\hline
\end{tabular}

Relationship between CASA and LPJ-GUESS NPP estimations for each land cover class is shown in Figure 9. 

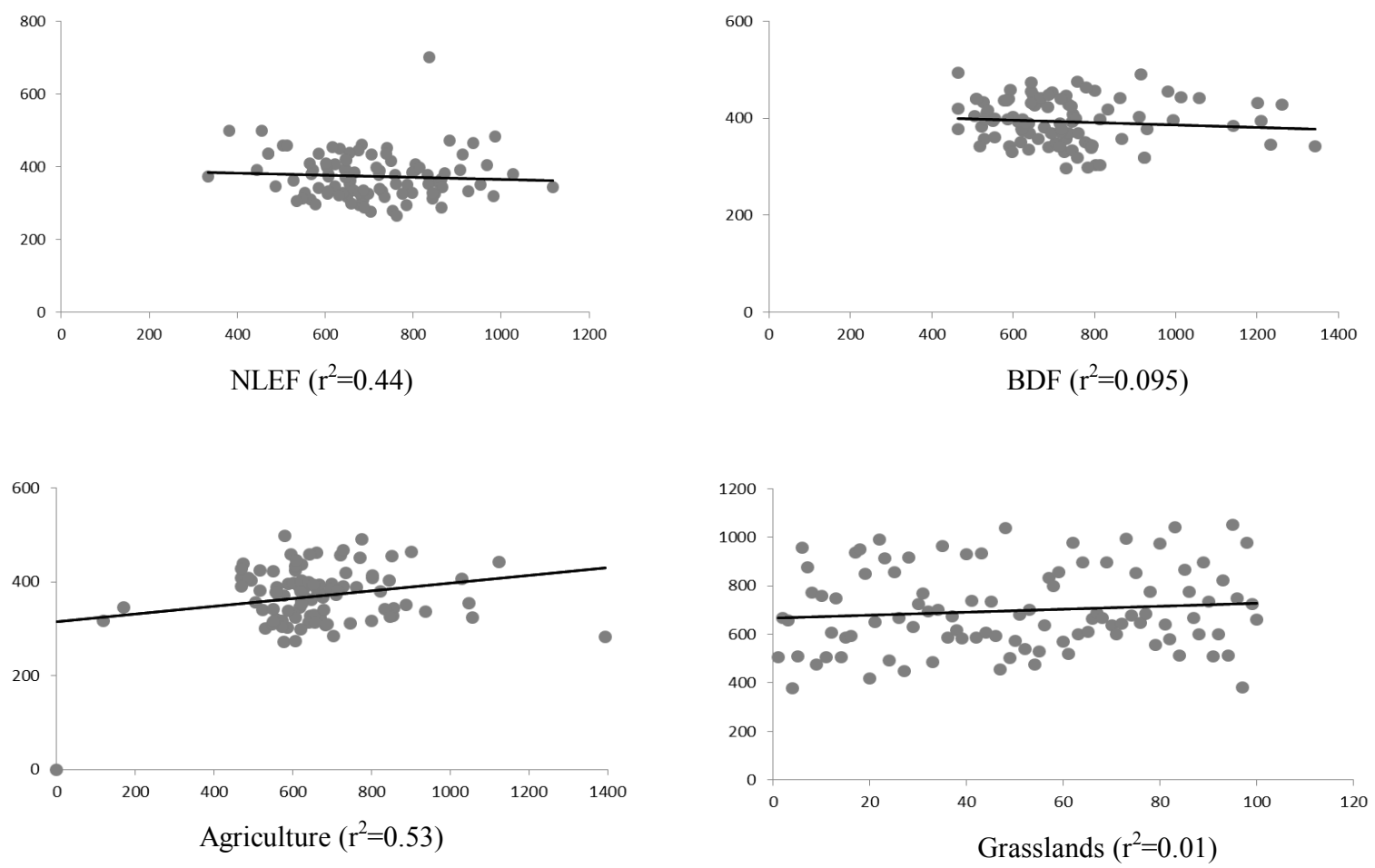

Figure 9. Relationship between CASA and LPJ-GUESS NPP estimations for each land covers class.

A comparison of the land cover classes indicates low correlation between two models. The correlation plots revealed general characteristics of the relationship between different model simulations. The correlation for NLEF estimations is 0.44 . The model estimations were slightly correlated for NLEF and Agriculture estimations. However, grasslands and BDF estimations within two models did not show a reasonable correlation.

\section{CONLUSIONS}

A remotely-sensed data based biogeochemical model and process-based modelling approach were performed and NPP outputs were compared to evaluate simulation performances of the models in a semi-arid Mediterranean environment. Each approach has a theoretical basis for its own at global scale and this study is important for applying global based models into watershed scale.

Model comparisons play an important role within numerous minor findings to improve simulation accuracy for further applications. In this comparative research, NPP estimations of different approaches varied greatly. The relation between CASA and LPJ simulations for NLEF was reasonable annually. Annually integrated agriculture NPP estimations showed also a reasonable correlation. The total annual NPP was underestimated with LPJ model in comparison to CASA results. However, taking the uncertainty related to scale differences between time-series and satellite data into account LPJ model performed well for a semi-arid region. The CASA model provided reasonable results to represent spatial distribution of NPP by means of remote-sensing integration. Thus, remote sensing provides many advantages to obtain relevant data that could be utilised in spatially-distributed NPP modelling.

\section{References:}

Potter, C. S., J. T. Randerson, C. B. Field, P. A. Matson, P. M. Vitousek, H. A. Mooney, and S. A. Klooster, 1993. Terrestrial ecosystem production: A process model based on global satellite and surface data, Global Biogeochem. Cycles, 7, $811-$ 841 ,.

Potter, C., Klooster S., Steinbach M., Tan P., Kumar V., Shekhar S., Nemani R., Myneni R., 2003. Global teleconnections of climate to terrestrial carbon flux. Journal of Geophysical Research, Vol. 108, NO. D17, 4556, doi:10.1029/2002JD002979.

Potter, C.S., Klooster, S., Steinbach, M., Tan, P., Sheikarand, S., and Carvalho, C., (2004). Understanding global teleconnections of climate to regional model estimates of Amazon ecosystem carbon fluxes. Global Change Biology, 10, $693-703$.

Loh, W.Y., 2002. Regression Trees with Unbiased Variable Selection and Interaction Detection, Statistica Sinica, 12 361386.

Dönmez, C., Berberoglu, S., and Curran, P.J. 2011. Modelling the current and future spatial distribution of Net Primary Production in a Mediterranean watershed. International Journal of Applied Earth Observation and Geoinformation, Volume 13: Issue 3, pp.336.-345.

Berberoglu, S., Evrendilek, F., Ozkan C., Donmez C., 2007. Modeling Forest Productivity Using Envisat MERIS Data. Sensors, 7, 2115-2127.

Rui Liu a, Jiu-lin Sun a, * , Juan-le Wang a, Min Liu b, Xiaolei Li c, Fei Yang a COMPARISON AND UNCERTAINTY ANALYSIS IN REMOTE SENSING BASED PRODUCTION EFFICIENCY MODELS, The International Archives of the Photogrammetry, Remote Sensing and Spatial Information Sciences, Vol. 38, Part II. 2010. 
Shugart, H.H. and West, D.C., 1980. Forest succession models. Bioscience 30, 308-313.

Sitch, S., Smith, B., Prentice, I.C., Arneth, A., Bondeau, A., Cramer, W., Kaplan, J.O., Levis, S., Lucht, W., Sykes, M.T., Thonicke, K., Venevsky, S., 2003. Evaluation of ecosystem dynamics, plant geography and terrestrial carbon cycling in the
LPJ dynamic global vegetation model. Global Change Biology 9, 161-185.

Hickler, Thomas, et al. (2012). "Projecting the future distribution of European potential natural vegetation zones with a generalized, tree species-based dynamic vegetation model." Global Ecology and Biogeography 21:50-63. 